\title{
Effects of dietary Docosahexaenoic, training and acute exercise on lipid mediators
}

\author{
X. Capó ${ }^{1,2}$, M. Martorell ${ }^{1,3}$, A. Sureda ${ }^{1,2}$, J. A. Tur ${ }^{1,2}$ and A. Pons ${ }^{1,2^{*}}$
}

\begin{abstract}
Background: Eicosanoids mediate initiation and resolution of inflammation. Our aim was evaluating the effects of training, exercise and docosahexaenoic (DHA) supplementation on plasma eicosanoids levels and peripheral blood mononuclear cells (PBMCs) eicosanoids production.

Methods: Fifteen male footballers were distributed to placebo and experimental groups. Experimental group consumed DHA-enriched beverage (1.16 g DHA/day) for 8 weeks, placebo group consumed a placebo beverage. Blood samples were taken before and after the nutritional intervention in basal conditions and $2 \mathrm{~h}$ after acute exercise.
\end{abstract}

Results: Training increased basal Prostaglandin E1 ( $\mathrm{PGE}_{1}$ ) plasma levels and PBMCs cyclooxygenase 2 (COX-2) protein levels in both groups, but COX-1 protein levels only in the experimental group. Acute exercise increased plasma PGE 2 and PBMCs active NFK $\beta$ levels. Lipopolysaccharide (LPS)-stimulated PBMCs increases eicosanoids production ( $\mathrm{PGE}_{1}, \mathrm{PGE}_{2}, \mathrm{RvD} 1$ ) in both groups and increased LPS-stimulated PBMCs active NFK $\beta$. DHA supplementation increased COX-2 levels but decreased LPS-stimulated PBMCs PGE 1 and PGE 2 production. Neither DHA supplementation nor acute exercise altered the expression of NFK 3, COX-2, 15-LOX2, 5-LOX, or IL-1 $\beta$ genes in PBMCs.

Conclusions: The increase of $\mathrm{PGE}_{1}$ plasma levels after training promoted systemic anti-inflammatory and vasodilator environment. Exercise and DHA supplementation acted synergistically by increasing plasma $\mathrm{PGE}_{2}$ with anti-inflammatory effects. Exercise primed PBMCs to enhance $P G E_{1}, P G E_{2}$ and RvD1 production in response to LPS.

Trial registration: The project was registered at ClinicalTrial.gov (NCT02177383).

Keywords: Inflammation, Docosahexaenoic acid, $\mathrm{PGE}_{1}, \mathrm{PGE}_{2}, \mathrm{RvD1}$, Lipid mediators, Exercise

\section{Background}

The practice of regular physical exercise has many health benefits, reducing the risk of suffering from several diseases such as cardiovascular disease, cancer, diabetes and osteoporosis [25]. Exercise exerts anti-inflammatory effects mediated by reduction of visceral fat mass [25], but may also be related to decreased levels of Toll-Like Receptors (TLRs) in monocytes [12] and to muscle production of bioactive compounds during contraction [29]. Each bout of acute

\footnotetext{
* Correspondence: antonipons@uib.es

1 Research Group on Community Nutrition and Oxidative Stress, Science Laboratory of Physical Activity, Department of Fundamental Biology and Health Sciences, University of Balearic Islands, Crtra. Valldemossa, km 7.5, E-07122 Palma de Mallorca, Illes Balears, Spain

${ }^{2}$ CIBER: CB12/03/30038 Pathophysiology of Obesity and Nutrition, CIBEROBN, Health Institute Carlos III (ISCIII), University of Balearic Islands, 07122 Palma de Mallorca, Spain

Full list of author information is available at the end of the article
}

exercise results in alterations in the pro/anti-inflammatory cytokine balance $[6,7,36]$. Moreover, the increased production of anti-inflammatory cytokines during exercise counteracts the production of pro-inflammatory cytokines associated to muscle damage, resulting in the instauration of an anti-inflammatory environment [28]. In addition, acute exercise alters the number and function of circulating immune cells [36], which are primed for their extravasation into tissues after exercise, thereby contributing to repair the damaged tissue [19].

Polyunsaturated omega- 3 fatty acids ( $\omega-3$ PUFA) contribute to regulate inflammation associated with chronic diseases including obesity, arthritis and atherosclerosis [4]. The anti-inflammatory effects of $\omega-3$ PUFA are evidenced by the inhibition of endotoxin-stimulated production of IL6 and IL8 in endothelial cells [18]. However, 
$\omega-3$ PUFA diet supplementation does not affect plasma cytokine response to strenuous exercise, which produces muscle damage and inflammation $[6,7,36]$. The antiinflammatory effects of $\omega-3$ PUFA are mediated by their participation in the regulation of the nuclear factor $\kappa \beta$ $(\mathrm{NF} \kappa \beta)$ signalling pathway and/or peroxisome proliferatoractivated receptor (PPAR $\gamma$ ) [3, 13]. The expression of proinflammatory genes via the $\mathrm{NF \kappa} \beta$ signalling pathway decreases after twelve weeks of $\omega$-3 PUFA diet supplementation [31]. $\omega-3$ PUFA diet supplementation also alters the function of immune cells [3], modulating chemotaxis and leukotriene generation in neutrophils by reducing arachidonic acid (AA) concentrations [20]. Eicosapentaenoic acid and docosahexaenoic acid (DHA) can compete with AA as a substrate for cyclooxygenase 2 (COX-2) and 5lipoxygenase (5-LOX), thus reducing the production of inflammatory mediators derived from AA. This process plays a critical role in the initial inflammatory response $[6,7,37]$. Prostaglandins (PGs) mediators arising from the COX-1 and COX-2 cascade from AA or its precursors are central to vascular responses, permitting neutrophils and monocytes to leave post capillary venules. PGs also play a role in the regulation of muscle protein metabolism [2], vasodilation, human skeletal muscle microcirculation, febrile and inflammatory responses [39], and initiation and timely resolution of inflammation [32]. Prostaglandin E1 $\left(\mathrm{PGE}_{1}\right)$ and prostaglandin E2 $\left(\mathrm{PGE}_{2}\right)$ are potent vasodilators which account for the increased blood flow in inflamed areas but $\mathrm{PGE}_{1}$ also regulates neutrophil function by reducing neutrophil activation [41]. Because of these vasodilator and immune properties, PGs are used as treatment for diseases derived from ischemia-reperfusion, such as arterial occlusive disease and venous ulcers [11, 22, 41].

The response of PGs to exercise has not been clearly established yet. Skeletal muscle produces PGs in response to muscular work, and this production is blocked by the intake of COX inhibitors, [22, 38]. Plasma $\mathrm{PGE}_{2}$ concentration increases in response to exercise or to muscle damage [1]. In other words, exercise increases $\mathrm{PGE}_{2}$ production as part of the inflammatory response, triggered by micro trauma occurring in skeletal muscles, [1]. In addition, $\mathrm{PGE}_{2}$ synthesis by infiltrating macrophages in the inflamed muscle increases $24-48 \mathrm{~h}$ after an exercise session [40]. It is also noticeable that downhill running for $45 \mathrm{~min}$ at $75 \% \mathrm{VO}_{2} \max$ increases circulating monocyte production of $\mathrm{PGE}_{2}$ [5]. The effects of $\mathrm{PGE}_{2}$ can be described as pro-inflammatory or anti-inflammatory depending on location, since $\mathrm{PGE}_{2}$ enhances LTB4mediated neutrophil extravasation and tissue injury, but it can also inhibit the $\mathrm{NFk} \beta$ signalling pathway in macrophages [21]. This inhibition plays a critical function in the initiation of resolution via lipid mediator class switching [32].
A new family of lipid mediators produced from the oxidation of $\omega-3$ PUFA including resolvins (Rvs), maresins and protectins has been described as pro-resolving mediators of inflammation [33]. The synthesis of these products involves COX and LOX pathways from DHA and EPA [33]. Rvs have been reported to reduce inflammation in chronic inflammatory diseases. Specifically, RvE1 and RvD1 inhibit trans-endothelial migration of neutrophils, preventing the infiltration of neutrophils into sites of inflammation, and RvD1 also inhibits IL1 $\beta$ production [34]. Plasma RvE1 and RvD1 have also been demonstrated to increase after acute exercise [22] but the participation of these lipid mediators in the antiinflammatory effects of acute exercise has not been studied.

The aim of this study was to evaluate the effects of regular training and DHA diet supplementation on plasma lipid mediators. The effects of DHA diet supplementation and acute exercise on plasma prostaglandins and on PBMC capabilities to produce cytokines, prostaglandins and pro-resolving mediators in response to lipopolysaccharide (LPS) stimulation were also analysed.

\section{Methods}

Subjects and anthropometric characteristics

Fifteen male soccer players from the Real Mallorca B team volunteered to participate in this study, 6 subjects took one liter of a placebo beverage five times a week and the other 9 an experimental beverage rich in DHA, over a period of 8 weeks. The subjects and study design was the same described previously $[6,7,23,24]$. At the beginning of the study, 22 subjects were recruited, but 6 of them left the football team during the experimental time and joined the first and professional team and one broke the anterior cruciate ligament of the knee. All subjects gave their written informed consent after an explanation of the experimental procedures and before commencement of the study. The study protocol was in accordance with the Declaration of Helsinki for research on human subjects and was approved by the Ethical Committee of Clinical Investigation of the CAIB (Palma de Mallorca, Balearic Islands, Spain). The project was registered at ClinicalTrial.gov (NCT02177383).

Height was determined using a mobile anthropometer (Kawe 44444, Asperg, Germany) to the nearest millimetre, with the subject's head in the Frankfurt plane. Body weight was determined to the nearest $100 \mathrm{~g}$ using a digital scale (Tefal, sc9210, Rumilly, France). The subjects were weighed in bare feet and light underwear, and the mean of three measurements was used $[6,7,23,24]$. Body mass index was calculated using the following equation: $[\mathrm{BMI}=$ mass $(\mathrm{kg}) /$ squared height $(\mathrm{m})]$. Participants in the study were $19.7 \pm 0.4$ years old, $76.5 \pm$ $2.5 \mathrm{~kg}$ weight, and $179.5 \pm 2.5 \mathrm{~cm}$ height. The waist 
circumference was $78.4 \pm 0.9 \mathrm{~cm}$, hip circumference was $97.4 \pm 1.2 \mathrm{~cm}$, waist-hip ratio (WHR) was $0.81 \pm 0.01$. The systolic blood pressure $119.5 \pm 6.5 \mathrm{mmHg}$, and $61.7 \pm$ $4.7 \mathrm{mmHg}$ for the diastolic blood pressure. The Body Mass Index (BMI) was $23.7 \pm 0.55, \mathrm{~kg} / \mathrm{m}^{2}$. The soccer players had $92.6 \pm 0.2 \%$ fat free mass. The $\mathrm{VO}_{2}$ max determined following the test of Leger-Boucher, was 61.4 \pm $1.35 \mathrm{~mL} / \mathrm{kg} \mathrm{min}$. There were no significant differences between groups in the anthropometric characteristics of players.

\section{DHA supplementation}

DHA was administered to the athletes using an almondbased isotonic beverage. Both placebo and supplemented beverages were made up of $3.0 \%$ almond and $0.8 \%$ sucrose and the rest was water, flavour, and added oils and vitamin E. Moreover, the placebo drink contained $0.8 \%$ refined olive oil whereas the experimental drink contained $0.6 \%$ refined olive oil and $0.2 \%$ wt \% DHA-S (DSM, Columbia, USA). The two almond beverages were manufactured by Liquats Vegetals S.A. (Girona, Spain) following an industrial process. Two beverages were made-up by: cinnamon and lemon natural flavours, sucrose, vitamin E, and the respective oil for the experimental (olive oil plus DHA-S) or placebo (olive oil) drink [6, 7, 23, 24]. Finally, the beverages were sterilized and packed. Both types of beverages were identical in taste and visual appearance. Beverages fatty acid composition was determined following the same procedure previously described [23, 24]. The experimental beverage had a significantly greater content of C20:3 (0.640 mg/100 ml of beverage), C22:0 (2.57 mg/ $100 \mathrm{ml}$ of beverage), C22:5 (56.1 mg/100 ml of beverage) and C22:6n3 (114 mg/100 ml of beverage) compared to the placebo beverage, in which these fatty acids were not present. No significant differences between beverages were evidenced in vitamin $\mathrm{E}$ content $(41.6 \mathrm{mg} / \mathrm{L}$ of beverage $\mathrm{n}$ placebo drink, and $45.7 \mathrm{mg} / \mathrm{L}$ of beverage in the experimental drink).

\section{Dietary intake and nutritional intervention}

Dietary habits of subjects were assessed using a 7-day dietary record questionnaire completed at the beginning of the study and in the week before the exercise test as previously described $[6,7,23,24]$. A qualified dietician verified and quantified the food records. All food items consumed were transformed into nutrients using a special computerized program based on the European and Spanish food composition tables $[6,7,23,24]$. DHA intake in the placebo group from the diet was $109 \pm$ $40.7 \mathrm{mg} /$ day, and DHA intake in the experimental group was $1209 \pm 40.7 \mathrm{mg} /$ day. The five times a week intake of $1 \mathrm{~L}$ of the supplemented beverage supposed a daily intake of about $1.14 \mathrm{~g}$ of DHA additional to the basal
DHA intake through the diet in the experimental group, whereas the placebo only took up DHA from the diet.

This nutritional intervention with the respective beverages for eight weeks is reflected in the erythrocytes fatty acid composition [23, 24].

\section{Experimental procedure}

For each subject two blood samples were taken at the end of the nutritional intervention, in basal conditions and after performing a soccer training session. The exercise consisted in a $2 \mathrm{~h}$ of habitual physical training session. After a 15 min warm-up, the players performed the Leger Boucher test. After that, players practiced a recovery exercise of control-passing for $15 \mathrm{~min}$. The main body of the training session was characterized by smallsided games. Briefly, the first exercise consists of 5 vs 5 possession exercise in an area of $20 \times 15 \mathrm{~m}$ (4 repetitions of $5 \mathrm{~min}$ with $30 \mathrm{~s}$ of recovery between repetitions); the second was a 6 vs 6 possession exercise in an area of 30 x $20 \mathrm{~m}$ (3 repetitions of $6 \mathrm{~min}$ with $1 \mathrm{~min}$ of recovery between repetitions), and finally, the players played a soccer match 5 vs 5 in $30 \times 40 \mathrm{~m}$ for $20 \mathrm{~min}$. The training session was designed to perform exercise intensity at more than $70 \% \mathrm{VO}_{2} \max$ over $50 \%$ duration of the session in order to induce an oxidative stress situation [35]. These conditions were followed by all participants in the study.

Blood samples used for analysis were collected from the same athletes, at the same time, using the same exercise protocols as previous described $[6,7,23,24]$. The blood samples used to measure prostaglandins and Rvs plasma levels, cytokine production and expression were the same as those previously used $[6,7]$.

\section{PBMCs purification}

Blood samples were centrifuged at $900 \mathrm{~g}$ at $4{ }^{\circ} \mathrm{C}$ for $30 \mathrm{~min}$ and the plasma was keep. The erythrocyte phase at the bottom was washed with PBS, centrifuged as above and finally erythrocytes were reconstituted with distilled water. The PBMCs fraction was purified from whole blood following an adaptation of the method previously described $[6,7]$ using Ficoll-Paque PLUS reagent (GE Healthcare ${ }^{\circ}$. An aliquot of PBMCs was used for LPS incubation.

\section{PBMC incubation with LPS}

Incubations of PBMCs were performed in RPMI 1640 culture media containing $2 \mathrm{mM}$ l-glutamine in the presence of the bacterial stimuli LPS. PBMCs obtained after 8 -week beverage supplementation in basal conditions and after exercise were diluted with RPMI 1640 culture media to $2 \times 10^{6}$ cells $/ \mathrm{ml}$ and activated by addition of LPS from Escherichia coli $(1 \mu \mathrm{g} / \mathrm{ml})$. Samples were incubated in polypropylene tubes at $37{ }^{\circ} \mathrm{C}$ for $2 \mathrm{~h}$. In a parallel 
experiment, an aliquot of PBMCs obtained after exercise were activated with LPS and incubated at either $37^{\circ} \mathrm{C}$ or $39.5{ }^{\circ} \mathrm{C}$ for $2 \mathrm{~h}$. Then, after shaking, the cells from both experiments were pelleted by centrifugation (900 g, $5 \mathrm{~min}$ ) and the cell-free supernatants were stored at $-70{ }^{\circ} \mathrm{C}$ for cytokine determinations.

\section{Active $\mathrm{NFK} \beta$ determination}

An isolated suspension of PBMCs was subjected to whole-cell protein extraction for the determination of NFk $\beta$ p50 activation, which was performed using the ELISA method TransAM NF-kB p50 Chemi according to the manufacturer's instructions (Active Motif ${ }^{\circledR}$ ). Briefly, the primary antibody used to detect $N F \kappa \beta$ recognizes an epitope on $\mathrm{p} 50$ that is accessible only when NFk $\beta$ is activated and bound to its DNA target.

\section{Cytokine and lipid mediator determination}

IL1 $\beta$ and MCP1 were measured in culture medium supernatant using ELISA kits. IL1 $\beta$ and MCP1 kits $\left(\right.$ RayBio $\left.^{\circ}\right)$; intra-assay and inter-assay reproducibility for both kits were lower than $10 \%$ and $12 \%$.

$\mathrm{PGE}_{1}$ and $\mathrm{PGE}_{2}$ were measured in plasma and in culture medium supernatant using ELISA kits (Enzo Life Sciences ${ }^{\oplus}$ ). Intra-assay and inter-assay reproducibility for $\mathrm{PGE}_{1}$ were lower than $10 \%$ and $12 \%$, respectively, while intra-assay and inter-assay reproducibility for $\mathrm{PGE}_{2}$ were lower than $6 \%$ in both cases.

RvD1 concentration in culture medium supernatants was determined using an RvD1 EIA Kit (Cayman $\left.{ }^{\circledR}\right)$, following the instructions manual. Intra-assay reproducibility was $10 \%$.

\section{PBMCs RNA extraction and real time PCR assay}

COX-2, NFk $\beta$, 15-LOX2, IL-1 $\beta$, 5-LOX mRNA levels were determined by multiplex real time PCR based on incorporation of a fluorescent reporter dye and using human $18 \mathrm{~S}$ rRNA as reference. For this purpose, total RNA was isolated from PBMCs by Tripure extraction (Roche Diagnostics ${ }^{\bullet}$ ). RNA $(1 \mu \mathrm{g})$ from each sample was reverse transcribed using $50 \mathrm{U}$ of Expand Reverse Transcriptase (Roche Diagnostics, Germany) and $20 \mathrm{pmol}$ oligo for $60 \mathrm{~min}$ at $37{ }^{\circ} \mathrm{C}$ in a $10 \mu \mathrm{L}$ final volume, according to manufacturer instructions. The resulting cDNA $(2.5 \mu \mathrm{L})$ was amplified using the Light-Cycler FastStart DNA MasterPLUS SYBR Green I kit (Roche Diagnostics ${ }^{\odot}$. Amplification was performed at $55{ }^{\circ} \mathrm{C}$ and 45 cycles. The relative quantification was performed by standard calculations considering $2(-\Delta \Delta \mathrm{Ct})$. Inflammatory gene expression levels before and after the session were normalized to the invariant control 18S rRNA. mRNA levels at the beginning of the stage were arbitrarily referred to as 1 . Primers used are $18 \mathrm{~S}$ forward (Fw): 5'-ATG TGA AGT CAC TGT GCC AG-3' and Reverse:
5'-GTG TAA TCC GTC TCC ACA GA-3' annealing temperature $60{ }^{\circ} \mathrm{C}$; COX-2 Fw: 5-TTG CTG GCA GGG TTG CTG GTG GTA-3', and Rv: 5'-CAT CTG CCT GCT CTG GTC AAT GGA A-3' annealing temperature $67{ }^{\circ} \mathrm{C}$; NFk $\beta$, Fw: $5^{\prime}$-AAA CAC TGT GAG GAT GGG ATC TG-3' Rv: 5' -CGA AGC CGA CCA CCA TGT-3' annealing temperature $60{ }^{\circ} \mathrm{C}$; $15-\mathrm{LOX} 2$, Fw: $5^{\prime}$-GCA TCC ACT GAT TGG ACC TT-3' and Rv: 5'-GCT GGC CTT GAA CTT CTG AC-3' annealing temperature $61^{\circ} \mathrm{C}$; IL$1 \beta$ Fw: $5^{\prime}$-GGA CAG GAT ATG GAG CAA CA-3', and Rv: 5' -GGC AGA CTC AAA TTC CAG CT -3' annealing temperature $58{ }^{\circ} \mathrm{C}$; 5-LOX, Fw: 5'-GGG CAT GGA GAG CAA AGA AG-3' and Rv: 5' -ACC TCG GCC GTG AAC GT-3' annealing temperature $59^{\circ} \mathrm{C}$.

\section{SDS-polyacrylamide gel electrophoresis and western blot analysis}

Cells were lysed with $250 \mu \mathrm{L}$ of RIPA buffer [250 mM Tris/ $\mathrm{HCl}, \mathrm{pH} 8.0,4.4 \% \mathrm{NaCl}, 5 \%$ IGEPAL $^{\circ}, 2.5 \%$ deoxycholic acid, $0.5 \%$ sodium dodecylsulfate (SDS)]. $20 \mu \mathrm{g}$ of proteins of total cell extract was loaded on $12 \%$ polyacrylamide gel, and were separated by size using SDS polyacrylamide gel. Following electrophoresis, samples were transferred onto a nitrocellulose membrane and incubated with a primary monoclonal antibody anti-COX-1 (1:1000) and anti-COX-2 (1:1000) $\left(\right.$ Cayman $\left.^{\circledast}\right)$.

Blots were then incubated with a secondary peroxidaseconjugated antibody $(1: 10,000)$, and the primary antibody was performed. Protein bands were visualized by ImmunStar $^{\oplus}$ Western $C^{\oplus}$ Kit reagent (Bio-Rad Laboratories) Western blotting detection systems. The chemiluminescence signal was captured with a Chemidoc XRS densitometer (Bio-Rad Laboratories ${ }^{\odot}$ ) and analyzed with Quantity One-1D Software (Bio-Rad Laboratories ${ }^{\circledast}$ ).

\section{Statistical analysis}

Statistical analysis was carried out using Statistical Package for Social Sciences (SPSS v.15.0 for Windows). Results are expressed as mean \pm SEM. and $P<0.05$ was considered statistically significant. A KolmogorovSmirnov test was applied to assess the normal distribution of the data. The statistical significance of the data was assessed by two-way analysis of variance (ANOVA). The statistical factors analysed were beverage supplementation $(S)$, acute exercise $(E)$, training season ( $\mathrm{T}$ ) and LPS stimulation (A). The data sets with a significant SxE, SxT, ExA, SxA and SxAxE interactions were tested by the ANOVA one-way test in order to identify groups who were different. When significant effects of $\mathrm{S}, \mathrm{E}, \mathrm{T}$ or A factor were found, a Student's t test for paired data was used to determine the differences between the groups involved. 


\section{Results}

Normality of the data was assessed using the KolmogorovSmirnov test and the dependent variable was normally distributed in each group that was compared in the ANOVA test.

\section{Regular training and DHA diet supplementation effects}

Training season and DHA diet supplementation significantly influenced PBMC counts. The training season increased circulating PBMCs from $2.79 \pm 0.16 \times 10^{3}$ to $3.34 \pm 0.15 \times 10^{3}$ cells $/ \mu \mathrm{L}$ in the placebo group, and from $3.23 \pm 0.29 \times 10^{3}$ to $3.99 \pm 0.34 \times 10^{3}$ cells $/ \mu \mathrm{L}$ in the experimental group. This increase only was significantly in the experimental group.
DHA diet supplementation for 8 weeks caused a variation in the DHA percentage on erythrocytes membrane (results not shown). The initial percentage of DHA respect to erythrocyte total fatty acid in placebo group $(7.37 \pm 0.27 \%)$ was maintained after the diet supplementation with placebo beverage $(8.40 \pm 0.41 \%)$, whereas the initial percentage of DHA in experimental group (7.93 \pm $0.54 \%)$ was significantly increased $(10.8 \pm 0.50 \%)$ to attain a significantly higher content than the placebo group.

Regular training of soccer players for 8 weeks significantly influenced the basal plasma levels of $\mathrm{PGE}_{1}$ whereas DHA diet supplementation significantly changed the basal plasma levels of $\mathrm{PGE}_{2}$ (Fig. 1). Plasma $\mathrm{PGE}_{1}$ significantly increased after 8 weeks of training in
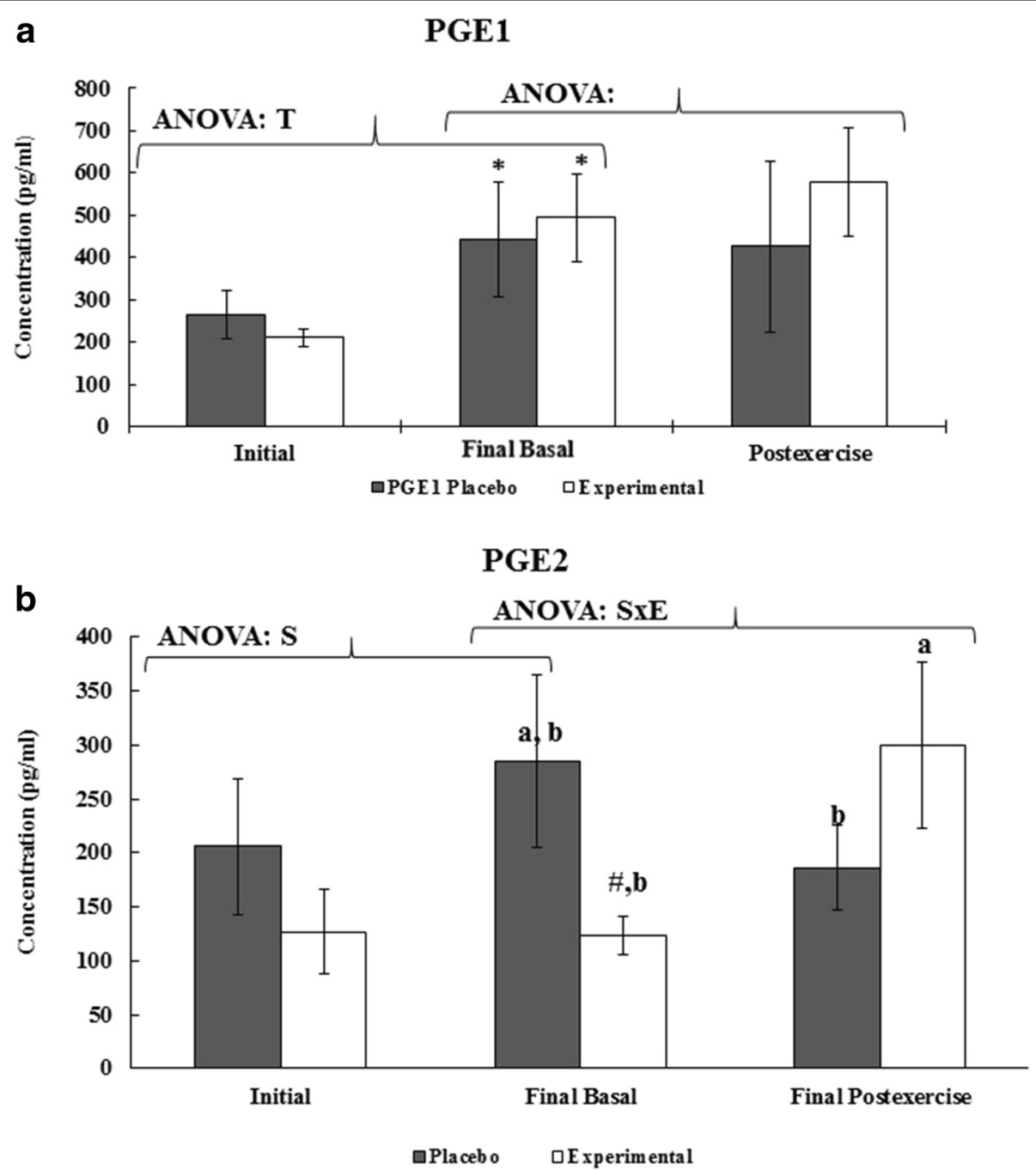

Fig. 1 Effects of acute exercise, DHA diet supplementation and training season on PGE1 and PGE2 plasma levels. Statistical analysis: Two-way ANOVA, $p<0.05$. (T) Significant effect of Training season, (S) Significant effect of Supplementation, (E) Significant effect of Acute Exercise, (ExT) Significant interaction between both factors. One-way ANOVA, $p<0.05$. (*) Significant difference between Initial and Final, (\#). Significant differences between Placebo and Experimental groups, (\$) Significant differences between the Basal and Post-exercise. When interaction exists between different groups, different letters reveal significant differences. Results are the mean \pm SEM 
both placebo and experimental groups, while plasma $\mathrm{PGE}_{2}$ maintained the initial basal levels. No significant differences were reported in $\mathrm{PGE}_{2}$ at the beginning of the intervention although its levels in the experimental group were lower than in the placebo. This trend was magnified after 8 weeks training reporting significant differences due to DHA diet supplementation.

Regular training but not DHA diet supplementation significantly influenced COX-1 and COX-2 protein levels in PBMCs (Fig. 2). Eight weeks of regular training significantly increased COX-1 and COX-2 protein levels in experimental group but not in placebo group.
Acute exercise and DHA diet supplementation effects Acute exercise did not influence PBMC counts, maintaining the basal values both in placebo and experimental groups (Placebo group: $3.34 \pm 0.15$ in basal conditions, $3.19 \pm 0.15$ after acute exercise; Experimental group: $3.99 \pm 0.34$ in basal conditions, $3.13 \pm 0.16$ after acute exercise, all $\mathrm{PBMC}$ results are expressed as $10^{3}$ cells $\left./ \mu \mathrm{L}\right)$.

The effects of acute exercise and DHA diet supplementation on $\mathrm{PGE}_{1}$ and $\mathrm{PGE}_{2}$ plasma levels are shown in Fig. 1. Acute exercise and DHA diet supplementation did not influence $\mathrm{PGE}_{1}$ plasma levels, whereas a statistically significant interaction between acute exercise and

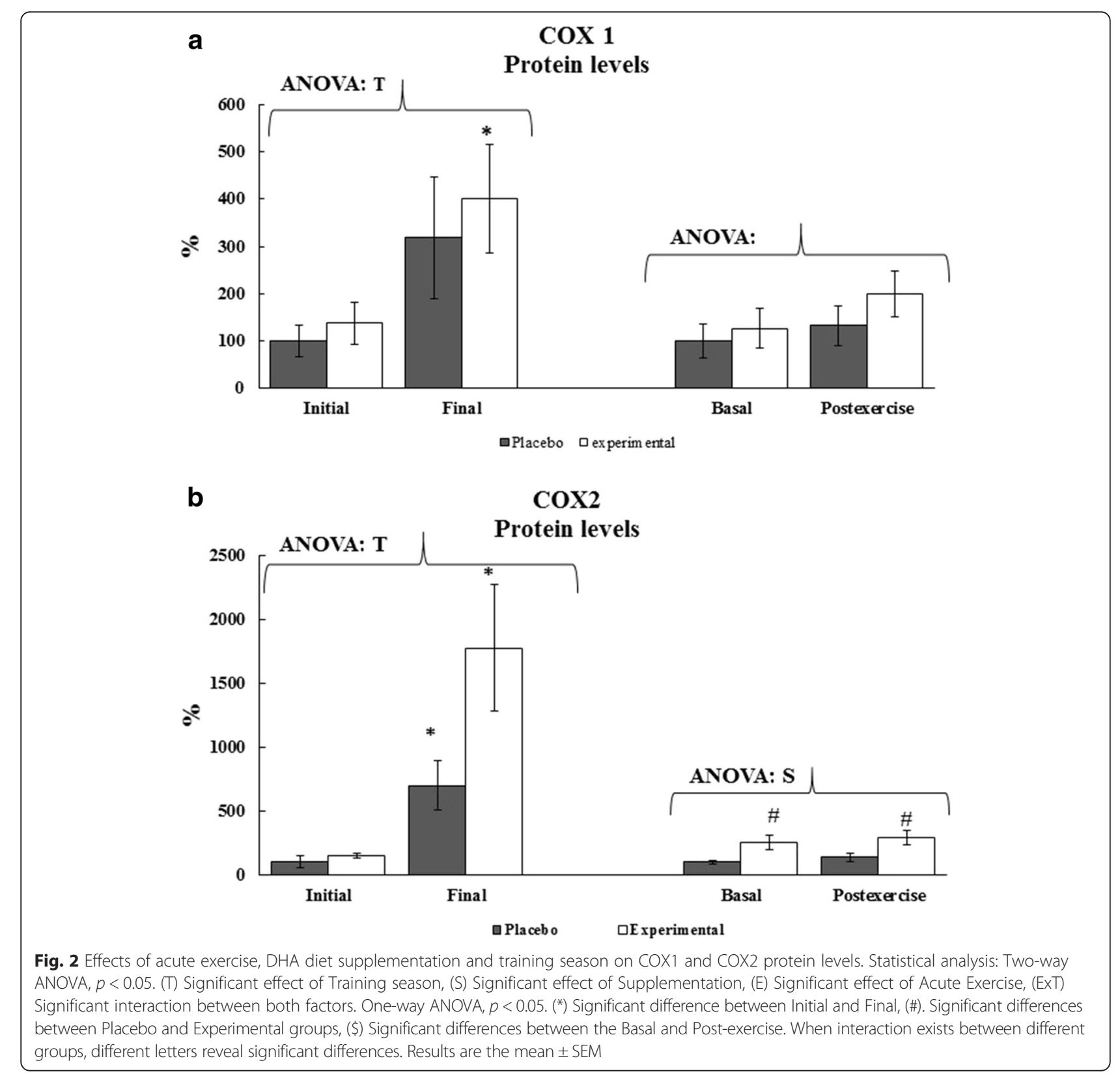


DHA diet supplementation was reported in plasma levels of $\mathrm{PGE}_{2}$. The experimental group showed significantly increased levels (about 2.4 times) of plasma $\mathrm{PGE}_{2}$ after acute exercise, whereas the placebo group maintained basal levels. This response resulted in higher $\mathrm{PGE}_{2}$ plasma levels in the experimental group (about 1.6 times) with respect to the placebo one.

The effects of DHA diet supplementation and acute exercise on the production rates of lipid mediators by LPS-stimulated PBMCs at $39.5{ }^{\circ} \mathrm{C}$ were also evaluated (Table 1). Acute exercise caused a significant increase in $\mathrm{PGE}_{1}$ and $\mathrm{PGE}_{2}$ production by LPS-stimulated PBMCs both in placebo and experimental groups. DHA diet supplementation significantly ameliorated the increase in both PGs production rate by LPS-stimulated PBMCs. The RvD1 production rate by LPS-stimulated PBMCs at $39.5{ }^{\circ} \mathrm{C}$ increased after acute exercise in both groups, but the increase was only significant (about 2.2 times) in the experimental group,

The effects of LPS-stimulation of PBMCs, acute exercise, and DHA diet supplementation on PBMC cytokine production are reported in Table 2. LPS-stimulation of PBMCs significantly increased IL1 $\beta$ basal production rate in both placebo (about 2.2 times) and experimental (about 1.8 times) groups, without any effect by DHA diet supplementation or acute exercise. No significant effects induced by LPS-stimulation or DHA diet supplementation were observed in MCP1 production rate. However, acute exercise significantly increased the MCP1 production rate by non-stimulated PBMCs, mainly in the experimental group; while no significant effects between groups of DHA diet supplementation were observed.

In order to evaluate the participation of $\mathrm{NF} \kappa \beta$ activation in the response to LPS-stimulation and to acute exercise, active NFk $\beta$ levels were determined in PBMCs (Fig. 3). Active $\mathrm{NF}_{\mathrm{K}} \beta$ levels significantly increased about $20 \%$ respect to the basal value after acute exercise. Basal PBMC incubation with LPS induced a significant increase of $27 \%$ and $35 \%$ in NFk $\beta$ activation at $37{ }^{\circ} \mathrm{C}$ and $39.5{ }^{\circ} \mathrm{C}$, respectively.
The effects of acute exercise and DHA diet supplementation on the expression of inflammatory and antiinflammatory genes, and COX-1 and COX-2 protein levels in PBMCs were determined (Table 3). No significant changes were observed in the expression of any of the evaluated genes due to acute exercise or DHA diet supplementation. Neither acute exercise nor DHA diet supplementation altered COX-1 protein levels in PBMCs (Fig. 2). COX-2 protein levels in PBMCs of the experimental group were significantly higher (about 2 times) than in the placebo group in both basal and postexercise conditions; although no effects were evidenced due to the acute exercise.

\section{Discussion}

\section{Effects on plasma prostaglandin levels}

PGs are relatively transient molecules with a half-life of only seconds to minutes, and they work in an autocrine and paracrine approach through specific receptors [38]. Despite this signalling role and short half-life, basal plasma levels of $\mathrm{PGE}_{1}$ and $\mathrm{PGE}_{2}$ observed in soccer players are relatively high. Both molecules show similar values to those of untrained male university students [16], higher than those of ironman sportsmen [1], and lower than post-menopausal or young women [9]. Regular training for 8 weeks practically duplicated the basal plasma levels of $\mathrm{PGE}_{1}$, but did not affect basal plasma levels of PGE $\mathrm{PG}_{2}$. Treatments with $\mathrm{PEG}_{1}$ are used to ameliorate several diseases related to ischemia-reperfusion [11]. In these studies, $\mathrm{PGE}_{1}$ treatment induced vasodilatation, inhibited platelet and leukocyte aggregation and decreased oedema formation during reperfusion. The dose of $\mathrm{PGE}_{1}$ used in these treatments increased plasma PGE1 levels up to values similar to the basal plasma $\mathrm{PGE}_{1}$ levels observed in soccer players after a training season. The anti-inflammatory and health effects of regular exercise $[25,29]$ could be related to increasing plasma basal $\mathrm{PGE}_{1}$ levels, taking into account the antiinflammatory and vasodilator role of $\mathrm{PGE}_{1}[11,39]$. There are several possible origins of plasma PGs as a

Table 1 Effects of acute exercise and DHA diet supplementation on lipid mediator PBMCs-stimulated production rates

\begin{tabular}{|c|c|c|c|c|c|c|c|}
\hline & & \multirow[t]{2}{*}{ Basal } & \multirow[t]{2}{*}{ Post-exercise } & \multicolumn{4}{|l|}{ ANOVA } \\
\hline & & & & $S$ & $E$ & SXE & $\mathrm{Fd}$ \\
\hline \multirow[t]{2}{*}{ PGE1 (pg/h $10^{6}$ cells) } & Placebo & $51,3 \pm 8,19$ & $159 \pm 25^{b}$ & $.000(F=12.32)$ & $.002(F=25.786)$ & $.102(F=2.917)$ & $(3,22)$ \\
\hline & Experimental & $22,6 \pm 6,47$ & $76,2 \pm 11,1^{b a}$ & & & & \\
\hline \multirow[t]{2}{*}{ PGE2 (pg/h $10^{6}$ cells) } & Placebo & $263 \pm 51,7$ & $615 \pm 114^{\mathrm{a}}$ & $.000(F=11.07)$ & $.003(F=22.787)$ & $.813(F=.057)$ & $(3,22)$ \\
\hline & Experimental & $46,5 \pm 14,7^{b}$ & $365 \pm 40,5^{\mathrm{ab}}$ & & & & \\
\hline \multirow[t]{2}{*}{ RvD1 (pg/h $10^{6}$ cells) } & Placebo & $4.24 \pm 0.74$ & $7.24 \pm 1,69$ & $.956(F=.003)$ & $.007(F=8.949)$ & $.0668(F=.189)$ & $(3,22)$ \\
\hline & Experimental & $3.79 \pm 0,39$ & $7.81 \pm 1,11^{b}$ & & & & \\
\hline
\end{tabular}

Statistical analysis: Two-way ANOVA, $p<0.05$., (S) Significant effect of Supplementation, (E) Significant effect of Acute Exercise, (ExS) Significant interaction between both factors. One-way ANOVA, $p<0.05$. ( $\left.{ }^{\mathrm{a}}\right)$ Significant differences between Placebo and Experimental groups, $\left({ }^{\mathrm{b}}\right)$ Significant differences between Basal and Post-exercise. When interaction exists between different groups, different letters reveal significant differences. Results are the mean \pm SEM. Fd means Freedom degree 
Table 2 Effects of LPS-stimulation, DHA diet supplementation and exercise on cytokine production rate by PBMCS

\begin{tabular}{|c|c|c|c|c|c|c|}
\hline & & \multicolumn{2}{|l|}{ Basal } & \multicolumn{2}{|l|}{ Post-exercise } & \multirow[t]{2}{*}{ ANOVA } \\
\hline & & NO LPS & LPS & NO LPS & LPS & \\
\hline \multirow[t]{3}{*}{$\mathrm{IL} 1 \beta$ (pg/h $10^{6}$ cells) } & Placebo & $6.22 \pm 1.46$ & $16.3 \pm 4.79 \$$ & $6.68 \pm 1.51$ & $21.1 \pm 7.34 \$$ & $\mathrm{~A}(.002)$ \\
\hline & & & & & & $(F=10.673)$ \\
\hline & Experimental & $9.35 \pm 2.24$ & $17.6 \pm 6.28 \$$ & $8.34 \pm 2.19$ & $21.7 \pm 8.07 \$$ & $\mathrm{Fd}(7,41)$ \\
\hline \multirow[t]{3}{*}{ MCP1 (pg/h $10^{6}$ cells) } & Placebo & $32.1 \pm 9.79$ & $36.1 \pm 4.07$ & $36.2 \pm 6.14$ & $45.4 \pm 3.87$ & $E(.002)$ \\
\hline & & & & & & $(F=10.437)$ \\
\hline & Experimental & $22.7 \pm 5.31$ & $29.6 \pm 4.98$ & $49.6 \pm 4.73 \#$ & $38.3 \pm 3.81$ & $\mathrm{Fd}(7,41)$ \\
\hline
\end{tabular}

Statistical analysis: Two-way ANOVA, $p<0.05$. S, Supplementation effect; A, LPS-stimulation effect, E, Exercise effect, SxA, interaction between Supplementation and LPS-stimulation effects, SxE, interaction between Supplementation and Exercise effects, ExA, interaction between Exercise and LPS activation effects, AxExS, interaction between effects of three factors. *Differences between Placebo and experimental groups; \#difference between Basal and Post-exercise conditions p; \$differences between NO LPS-stimulated and LPS-stimulated groups. When interaction exists between different groups, different letters reveal significant differences. Results are the mean \pm SEM. Fd means Freedom degree

result of the ubiquitous presence of COX enzymes, including muscle, immune cells and platelets; therefore muscle could be a source of PGs during exercise [38]. Regular exercise training per se influences the phospholipid fatty acid composition of muscle membranes, but has no effect on the composition of fatty acids stored in triacylglycerol within the muscle [15]. A training season was able to induce changes in the muscle phospholipid composition in such a way as to enhance the capabilities to $\mathrm{PGE}_{1}$ synthesis, in accordance with the increased plasma $\mathrm{PGE}_{1}$ levels present after 8 weeks of training. The different pattern for plasma $\mathrm{PGE}_{1}$ and $\mathrm{PGE}_{2}$ in response to training and DHA diet supplementation is not surprising, given the different biosynthesis pathways of these two PGs [30]. $\mathrm{PGE}_{2}$ is synthesized from AA (C20:4 $\Delta 5,8,11,14$ ) [30], whereas $\mathrm{PGE}_{1}$ is synthesized from dihomo- $\gamma$-linolenic acid (DGLA) (C20:3 $\Delta 8,11,14$ ), a precursor of AA [30]. The relative differences of plasma
$\mathrm{PGE}_{2}$ versus $\mathrm{PGE}_{1}$ levels is not merely a function of the relative abundance of AA versus DGLA in tissues, but could also be related to the different cellular metabolism of these two fatty acids. Chronic exercise induces changes in the enzyme activities related to eicosanoid metabolism [26]; elongase activity increases but $\Delta 5$ - and $\Delta 9$-desaturase activities have no consistent changes attributed to chronic exercise [26], although $\Delta 5$-desaturase was found to be generally lower in muscles of trained rats [14]. Due to the limited activity of $\Delta 5$-desaturase, most DGLA is inserted into membrane phospholipids at the same C-2 position as for AA [30]. This picture is in accordance with the effects of a training season on basal plasma $\mathrm{PGE}_{1}$ levels enhancing DGLA availability in muscle phospholipids, in order to facilitate $\mathrm{PGE}_{1}$ synthesis via an increase in COX-1 and COX-2 muscle activities. It is also in accordance with a lack of effects of exercise on the fatty acid composition of muscle lipids

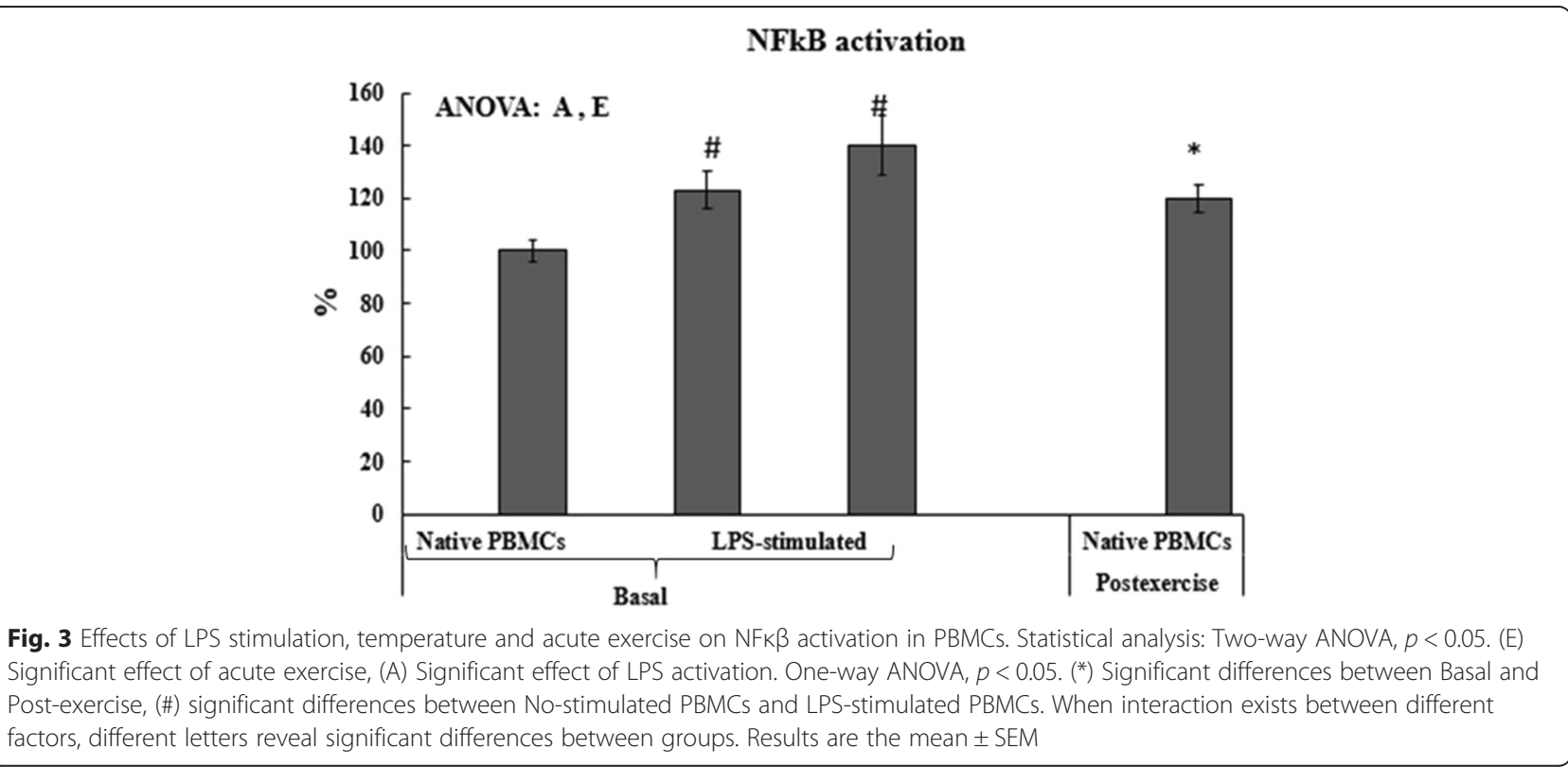


Table 3 Effects of DHA diet supplementation and exercise on PBMCs gene expression

\begin{tabular}{|c|c|c|c|c|c|c|c|}
\hline & & \multirow[t]{2}{*}{ Basal } & \multirow[t]{2}{*}{ Post-exercise } & \multicolumn{4}{|l|}{ ANOVA } \\
\hline & & & & $S$ & $E$ & SxE & $\mathrm{Fd}$ \\
\hline \multirow[t]{2}{*}{$\mathrm{NFK \beta}(\mathrm{AU})$} & Placebo & $1.00 \pm 0.22$ & $1.21 \pm 0.31$ & $.576(f=.373)$ & $.369(f=.142)$ & $.906(f=.006)$ & $(3,42)$ \\
\hline & Experimental & $1.33 \pm 0.33$ & $1.46 \pm 0.33$ & & & & \\
\hline \multirow[t]{2}{*}{ COX-2 (AU) } & Placebo & $1.00 \pm 0.28$ & $1.99 \pm 0.86$ & $.355(f=.026)$ & $.726(f=.592)$ & $.513(f=.142)$ & $(3,42)$ \\
\hline & Experimental & $1.46 \pm 0.45$ & $1.80 \pm 0.51$ & & & & \\
\hline \multirow[t]{2}{*}{ 15-LOX2 (AU) } & Placebo & $1.00 \pm 0.37$ & $1.43 \pm 0.76$ & $.402(f=.717)$ & $.973(f=.001)$ & $.983(f=.000)$ & $(3,45)$ \\
\hline & Experimental & $1.03 \pm 0.30$ & $1.43 \pm 0.43$ & & & & \\
\hline \multirow[t]{2}{*}{ 5-LOX (AU) } & Placebo & $1.00 \pm 0.28$ & $1.10 \pm 0.42$ & $.694(f=.109)$ & $.742(f=.157)$ & $.956(f=.003)$ & $(3,52)$ \\
\hline & Experimental & $0.89 \pm 0.21$ & $1.02 \pm 0.18$ & & & & \\
\hline \multirow[t]{2}{*}{$\operatorname{IL} 1 \beta(A U)$} & Placebo & $1.00 \pm 0.34$ & $0.84 \pm 0.17$ & $.906(f=.000)$ & $.998(f=.014)$ & $.496(f=.472)$ & $(3,42)$ \\
\hline & Experimental & $0.80 \pm 0.22$ & $1.03 \pm 0.29$ & & & & \\
\hline
\end{tabular}

Statistical analysis: Two-way ANOVA. (S) Significant effect of supplementation, (E) Significant effect of exercise, (SxE) Significant interaction between both factors. (\#)Significant differences between Placebo and Experimental groups. $\left.{ }^{*}\right)$ Significant differences between the Pre-exercise and Post-exercise. $p<0.05$. When interaction exists between different groups, different letters reveal significant differences. Results are the mean $\pm \mathrm{SEM}$. Fd means Freedom degree. AU means arbitrary units referred to Pre-exercise Placebo values

reported by a nutritional intervention [26], because no effects of DHA diet supplementation are observed on the plasma levels of $\mathrm{PGE}_{1}$.

Acute exercise increases intramuscular $\mathrm{PGE}_{2}$ levels [17], and also increases or does not affect $\mathrm{PGE}_{2}$ plasma levels [9], which are attributed to muscle $\mathrm{PGE}_{2}$ production. Neither DHA diet supplementation nor acute exercise altered. $\mathrm{PGE}_{2}$ plasma levels, but these two factors interact resulting in a significant increase in plasma $\mathrm{PGE}_{2}$ levels after acute exercise in the experimental group. $\mathrm{PGE}_{2}$ has pro-inflammatory or anti-inflammatory effects depending on location: it enhances LTB4mediated neutrophil extravasation and tissue injury, but it inhibits the NFK $\beta$ signalling pathway via the EP4 receptor, the LPS-induced IL6 release [26], and plays a critical role in the initiation of lipid mediator class switching [32]. $\mathrm{PGE}_{2}$ has been evidenced to suppress lymphocyte proliferation and natural killer cell activity, and to inhibit the production of TNF $\alpha$, IL1, IL6, IL2 and IFNY [4]. Acute exercise and DHA diet supplementation have synergistic effects against inflammation by enhancing $\mathrm{PGE}_{2}$ levels in plasma. These results could reinforce the idea that practising regular exercise results in health benefits and reduces the risk of inflammation related diseases [25].

\section{Effects on PBMC capabilities to produce lipid mediators and cytokines}

It is well established that dietary $\omega-3$ PUFA alters the fatty acid composition of immune cells [36]. This altered fatty acid composition could affect immune cell function $[6,7]$ and the capability to produce cytokines and lipid mediators. Similarly, training per se alters the fatty acid composition of phospholipids and enzyme activities of the eicosanoid metabolism [26]. Protein levels of COX-1 and COX-2 significantly increased in PBMCs after 8 weeks of a training season, mainly in the DHA supplemented group. In addition, this is the first time that an enhancing effect of DHA diet supplementation on COX2 levels has been described in PBMCs. This could indicate greater capabilities of PBMCs after training and after acute exercise in the DHA supplemented group to transform DGLA into $\mathrm{PGE}_{1}$ or $\mathrm{AA}$ into $\mathrm{PGE}_{2}$, which in fact could increase basal plasma $\mathrm{PGE}_{1}$ and $\mathrm{PGE}_{2}$ levels; however, the changes in $\mathrm{PGE}_{1}$ and $\mathrm{PGE}_{2}$ plasma levels are not consistent with these pictures. This suggests that PBMCs are not responsible for plasma $\mathrm{PGE}_{1}$ and $\mathrm{PGE}_{2}$ levels, even after acute exercise. COX-2 protein levels were significantly higher in the DHA diet supplemented group than in the placebo group, both in basal and postexercise conditions. These results are in accordance with previous studies, in which an increase in both COX2 activity and protein levels was observed after resistance exercise, and this increase was maintained among $24 \mathrm{~h}$ [8]. The COX-2 isoform is inducible and is involved in febrile and inflammatory responses [38], whereas the COX-1 isoform is constitutively expressed in most cells and catalyzes the production of PGs involved in homeostatic control and cell maintenance. Synergistic effects of DHA diet supplementation and acute exercise on PBMC COX-2 levels are not reflected in the rate of $\mathrm{PGE}_{1}$ and $\mathrm{PGE}_{2}$ production by LPS-stimulated PBMCs. It seems that increased levels of COX-2 have no functional consequences, because DHA diet supplementation decreases the production rate of $\mathrm{PGE}_{1}$ and $\mathrm{PGE}_{2}$ by LPSstimulated PBMCs. Discordances between COX protein levels and COX activity have been previously described [8]. Acute exercise transiently increased COX-1 activity in muscle independently of COX-1 protein levels; in contrast, both COX-2 activity and protein levels were 
elevated with exercise and this rise persists until at least $24 \mathrm{~h}$ after resistance exercise [8]. In contrast, DHA diet supplementation did not alter gene expression of $\mathrm{NF \kappa} \beta$, COX-2, 15-LOX2, IL1 $\beta$ or 5-LOX in PBMCs, even after acute exercise.

LPS-stimulated PBMCs also synthesize RvD1. Rvs are lipid mediators produced from $\omega-3$ PUFA such as EPA (Resolvin E) and DHA (Resolvin D) [33]. RvD1 is produced from DHA through a pathway initiated by COX-2 $[33,34]$. Oil fish diet supplementation has been demonstrated to increase leucocyte capabilities to produce Rvs [33]. RvD1 has pro-resolving and anti-inflammatory properties by inhibiting trans-endothelial migration of neutrophils, preventing their infiltration into sites of inflammation and inhibiting IL1 $\beta$ production $[33,34]$. The RvD1 production rate by LPS-stimulated PBMCs was significantly increased after exercise, mainly in the DHA supplemented group. Rvs are synthesized by immune cells after initiation of inflammation in order to contribute to its complete resolution and returning to homeostasis [32]. These results are in accordance with previous studies showing an increase in RvD1 serum levels after acute exercise [22], which could be related in part to the anti-inflammatory effects of regular exercise [25]. LPSstimulated PBMCs simulate the effects of an infection. In self-limited Escherchia coli infections, resolution programs were activated in mice, and RvD1 and RvD5 were elevated [10] in accordance with the effects of LPS activation on RVD1 production rate by PBMCs. The greater capabilities to produce RVD1 by LPS-stimulated PBMCs at post-exercise respect to basal could indicate that postexercise circulating immune cells are switching in order to resolve inflammation to a greater extent than basal samples. More studies are needed to assess whether other lipid mediators influence the anti-inflammatory effects associated with physical exercise.

LPS stimulates PBMC basal production rate of cytokines such as IL6, IL8, and TNF $[6,7]$. LPS links to TLR4 by activating the $N F \kappa \beta$ pathway and inducing an inflammatory response [27], which was evidenced by increased NFK $\beta$ activation after LPS-stimulation of PBMCs at $37{ }^{\circ} \mathrm{C}$ and $39.5{ }^{\circ} \mathrm{C}$ and increased basal rate of IL1b production. Acute exercise also increased active $\mathrm{NF}_{\mathrm{N}} \beta$ in PBMCs, but it was in parallel with a lack of acute exercise effects on the expression of inflammatory genes. Active NFk $\beta$ translocates to the nucleus allowing the expression of inflammatory genes but additional stimulus must be operative to enhance the expression of NFk $\beta$, COX-2, 15-LOX2, IL1 $\beta$ and 5-LOX in PBMCs after acute exercise. Acute exercise increased active $N F \kappa \beta$ levels priming PBMCs for inflammatory response.

Acute exercise increased PBMC production rate of MCP1 and also primes PBMCs to respond to LPSstimulation in order to enhance their $\mathrm{PGE}_{1}, \mathrm{PGE}_{2}$, RvD1 and MCP1 production. These results are in accordance with increased levels of TLR4 found in PBMCs after acute exercise, and with the higher rate of cytokine production after LPS-stimulation of post-exercise PBMCs $[6,7]$. DHA diet supplementation attenuated the response of acute exercise to stimulation of PBMCs with LPS. The anti-inflammatory effects of DHA-diet supplementation have been described in previous studies $[6,7,36]$. DHAsupplementation attenuates the effects of acute exercise by increasing TLR4 levels in PBMCs [6, 7]. $\omega-3$ PUFA can interfere with TLR4 activation by LPS; this process inhibits signalling components downstream from TLR4 but can also directly prevent $N F \kappa \beta$ activation by impeding $I-\kappa \beta$ phosphorylation and therefore prevent $\mathrm{NF} \kappa \beta$ translocation into the nucleus [27].

\section{Conclusion}

In summary, regular training promotes systemic antiinflammatory and vasodilator effects by increasing PGE $_{1}$. Acute exercise and DHA diet supplementation act synergistically by increasing plasma $\mathrm{PGE}_{2}$ and also with anti-inflammatory effects. Acute exercise primes PBMCs to enhance $\mathrm{PGE}_{1}, \mathrm{PGE}_{2}$ and RvD1 production rates in response to LPS, with a higher anti-inflammatory and resolute profile for PBMCs after exercise. The differences between eicosanoid production by PBMCs and plasma eicosanoid levels reinforce the idea that PBMCs are not the main contributors to plasma $\mathrm{PGE}_{2}$ and $\mathrm{PGE}_{1}$ after acute exercise.

Finally, prescription of regular exercise, similar to football training, could produce anti-inflammatory effects associated to an increase in PGE1 and PGE2 levels. Furthermore, the enhancement of muscular prostaglandins synthesis, probably trough exercise, could subserve these anti-inflammatory and vasodilator effects. In addition, acute exercise and DHA supplementation can act synergistically in the induction of anti-inflammatory response, but also both factors may reduce the inflammatory response induced by pathogen-associated molecular pattern (PAMPs) as LPS.

\section{Limitation of the study}

The experimental procedure was designed to perform exercise at intensity higher than $70 \% \mathrm{VO}_{2} \max$ for more than $50 \%$ duration of the session in order to induce an oxidative stress situation. These conditions were followed by all participants in the study; however, we did not realized any quantification of the effort using portable metabolic carts, activity monitors or video analysis to confirm energy expenditure or movement pattern, and this fact could be the main limitation of the study. Another limitation was low number of participant in each group. Twenty-two athletes, eleven in each group, participate in the trail at the beginning of the study; 
unfortunately, six athletes left the football team during the trial to join the first and professional team and one broke the anterior cruciate ligament of the knee.

\section{Abbreviations}

AA: arachidonic acid; ANOVA: analysis of variance; BMI: body mass index; COX: cyclooxygenase; DGLA: dihomo- $\gamma$-linolenic acid; DHA: docosahexaenoic acid; IFNY: interferon gamma; IL1: interleukin 1; IL1 $\beta$ : interleukin 1 $\beta$; IL2: interleukin 2; IL6: Interleukin 6; LOX: Iypoxigenase; LPS: lipopolysaccharide; MCP1: monocyte chemotactic protein 1; NFK $\beta$ : nuclear factor $\mathrm{k} \beta$ : PAMPs: pathogen-associated molecular pattern; PBMCs: peripheral blood mononuclear cells increased basal; PGE: prostaglandin E; PPARY: proliferatoractivated receptor; PUFA: polyunsaturated fatty acids; RVD1: resolvine D1; TLR: toll like receptor; TNFa: tumour necrosis factor a; WHR: waist-hip ratio.

\section{Competing interests}

The authors declare that they have no competing interests.

\section{Authors' contributions}

XC, MM, AS, JAT, and AP conception and design of research; XC, MM, and AS performed experiments; $X C, M M$, and $A S$, analysed data; $X C$ interpreted results of experiments; $X C$ drafted manuscript; $A S, M M, J A T$, and AP edited and revised manuscript; $A S, J A T$, and AP approved final version of manuscript. All authors read and approved the final manuscript.

\section{Acknowledgments}

Acción Estratégica en Salud del Ministro de Ciencia e Innovación DPS200807033-C03-03, Programme of Promotion of Biomedical Research and Health Sciences, Projects 11/01791, Red Predimed-RETIC RD06/0045/1004, CIBERobn CB12/03/30038 and Balearic Island Government and FEDER founds (35/2011 and 23/2012). We hereby acknowledge the PhD grant provided by the University of the Balearic Islands.

\section{Author details}

${ }^{1}$ Research Group on Community Nutrition and Oxidative Stress, Science Laboratory of Physical Activity, Department of Fundamental Biology and Health Sciences, University of Balearic Islands, Crtra. Valldemossa, km 7.5, E-07122 Palma de Mallorca, Illes Balears, Spain. ${ }^{2}$ CIBER: CB12/03/30038 Pathophysiology of Obesity and Nutrition, CIBEROBN, Health Institute Carlos III (ISCIII), University of Balearic Islands, 07122 Palma de Mallorca, Spain. ${ }^{3}$ Department of Nutrition and Dietetics, Faculty of Pharmacy, University of Concepción, 4070386 Concepción, Chile.

Received: 11 December 2015 Accepted: 24 March 2016

Published online: 05 April 2016

\section{References}

1. Bassit RA, Curi R, Costa Rosa LF. Creatine supplementation reduces plasma levels of pro-inflammatory cytokines and PGE2 after a half-ironman competition. Amino Acids. 2008:35:425-31.

2. Burd NA, Dickinson JM, Lemoine JK, Carroll CC, Sullivan BE, Haus JM, Jemiolo B, Trappe SW, Hughes GM, Sanders CE, Jr., Trappe TA. Effect of a cyclooxygenase-2 inhibitor on postexercise muscle protein synthesis in humans. Am J Physiol Endocrinol Metab. 2010;298:E354-361.

3. Calder PC. Polyunsaturated fatty acids and inflammatory processes: New twists in an old tale. Biochimie. 2009;91:791-5.

4. Calder PC, Grimble RF. Polyunsaturated fatty acids, inflammation and immunity, Eur J Clin Nutr. 2002:56 Suppl 3:S14-19.

5. Cannon JG. Inflammatory Cytokines in Nonpathological States. News Physiol Sci. 2000;15:298-303.

6. Capo X, Martorell M, Llompart I, Sureda A, Tur JA, Pons A. Docosahexanoic acid diet supplementation attenuates the peripheral mononuclear cell inflammatory response to exercise following LPS activation. Cytokine. 2014;69:155-64.

7. Capo X, Martorell M, Sureda A, Llompart I, Tur JA, Pons A. Diet supplementation with DHA-enriched food in football players during training season enhances the mitochondrial antioxidant capabilities in blood mononuclear cells. Eur J Nutr. 2015;54(1):35-49.

8. Carroll CC, O'Connor DT, Steinmeyer R, Del Mundo JD, McMullan DR, Whitt JA, Ramos JE, Gonzales RJ. The influence of acute resistance exercise on cyclooxygenase-1 and -2 activity and protein levels in human skeletal muscle. Am J Physiol Regul Integr Comp Physiol. 2013;305:R24-30.

9. Conceicao MS, Libardi CA, Nogueira FR, Bonganha V, Gaspari AF, Chacon-Mikahil MP, Cavaglieri CR, Madruga VA. Effects of eccentric exercise on systemic concentrations of pro- and anti-inflammatory cytokines and prostaglandin (E2): comparison between young and postmenopausal women. Eur J Appl Physiol. 2012;112:3205-13.

10. Chiang N, Fredman G, Backhed F, Oh SF, Vickery T, Schmidt BA, Serhan CN Infection regulates pro-resolving mediators that lower antibiotic requirements. Nature. 2012;484:524-8.

11. Frassdorf J, Luther B, Mullenheim J, Otto F, Preckel B, Schlack W, Thamer V. Influence of groin incision, duration of ischemia, and prostaglandin E1 on ischemia-reperfusion injury of the lower limb. J Cardiothorac Vasc Anesth. 2006;20:187-95

12. Gleeson M, McFarlin B, Flynn M. Exercise and Toll-like receptors. Exerc Immunol Rev. 2006;12:34-53.

13. Hassan A, Ibrahim A, Mbodji K, Coeffier M, Ziegler F, Bounoure F, Chardigny JM, Skiba M, Savoye G, Dechelotte P, Marion-Letellier R. An alpha-linolenic acid-rich formula reduces oxidative stress and inflammation by regulating NF-kappaB in rats with TNBS-induced colitis. J Nutr. 2010;140:1714-21.

14. Helge JW, Ayre KJ, Hulbert AJ, Kiens B, Storlien LH. Regular exercise modulates muscle membrane phospholipid profile in rats. J Nutr. 1999; 129:1636-42.

15. Helge JW, Wu BJ, Willer M, Daugaard JR, Storlien LH, Kiens B. Training affects muscle phospholipid fatty acid composition in humans. J Appl Physiol (1985). 2001;90:670-7.

16. Hirose L, Nosaka K, Newton M, Laveder A, Kano M, Peake J, Suzuki K. Changes in inflammatory mediators following eccentric exercise of the elbow flexors. Exerc Immunol Rev. 2004;10:75-90.

17. Karamouzis M, Karamouzis I, Vamvakoudis E, Ampatzidis G, Christoulas K, Angelopoulou N, Mandroukas K. The response of muscle interstitial prostaglandin $\mathrm{E}(2)(\mathrm{PGE}(2))$, prostacyclin I(2)(PGI(2)) and thromboxane $A(2)(T X A(2))$ levels during incremental dynamic exercise in humans determined by in vivo microdialysis. Prostaglandins Leukot Essent Fat Acids. 2001;64:259-63.

18. Khalfoun B, Thibault F, Watier H, Bardos P, Lebranchu Y. Docosahexaenoic and eicosapentaenoic acids inhibit in vitro human endothelial cell production of interleukin-6. Adv Exp Med Biol. 1997:400b:589-97.

19. LaVoy EC, Bosch JA, Lowder TW, Simpson RJ. Acute aerobic exercise in humans increases cytokine expression in CD27(-) but not CD27(+) CD8(+) T-cells. Brain Behav Immun. 2013:27:54-62

20. Lee TH, Hoover RL, Williams JD, Sperling Rl, Ravalese 3rd J, Spur BW, Robinson DR, Corey EJ, Lewis RA, Austen KF. Effect of dietary enrichment with eicosapentaenoic and docosahexaenoic acids on in vitro neutrophil and monocyte leukotriene generation and neutrophil function. N Engl J Med. 1985;312:1217-24.

21. Liu Y, Chen LY, Sokolowska M, Eberlein M, Alsaaty S, Martinez-Anton A, Logun C, Qi HY, Shelhamer JH. The fish oil ingredient, docosahexaenoic acid, activates cytosolic phospholipase A2 via GPR120 receptor to produce prostaglandin E2 and plays an anti-inflammatory role in macrophages. Immunology. 2014;143(1):81-95.

22. Markworth JF, Vella L, Lingard BS, Tull DL, Rupasinghe TW, Sinclair AJ, Maddipati KR, Cameron-Smith D. Human inflammatory and resolving lipid mediator responses to resistance exercise and ibuprofen treatment. Am J Physiol Regul Integr Comp Physiol. 2013;305:R1281-1296.

23. Martorell M, Capo X, Bibiloni MM, Sureda A, Mestre-Alfaro A, Batle JM, Llompart I, Tur JA, Pons A. Docosahexaenoic Acid Supplementation Promotes Erythrocyte Antioxidant Defense and Reduces Protein Nitrosative Damage in Male Athletes. Lipids. 2015;50(2):131-48.

24. Martorell M, Capo X, Sureda A, Tur JA, Pons A. Effects of docosahexaenoic acid diet supplementation, training, and acute exercise on oxidative balance in neutrophils. Appl Physiol Nutr Metab. 2014:39:446-57.

25. Mathur N, Pedersen BK. Exercise as a mean to control low-grade systemic inflammation. Mediat Inflamm. 2008:2008:109502.

26. Nikolaidis MG, Mougios V. Effects of exercise on the fatty-acid composition of blood and tissue lipids. Sports Medicine (Auckland, NZ). 2004;34:1051-76.

27. Pahl HL. Activators and target genes of Rel/NF-kappaB transcription factors. Oncogene. 1999:18:6853-66.

28. Pedersen BK. Muscle as a secretory organ. Compr Physiol. 2013;3:1337-62.

29. Pedersen BK, Hoffman-Goetz L. Exercise and the immune system: regulation, integration, and adaptation. Physiol Rev. 2000;80:1055-81. 
30. Rubin D, Laposata M. Regulation of agonist-induced prostaglandin E1 versus prostaglandin E2 production. A mass analysis. J Biol Chem. 1991;266:23618-23.

31. Schmidt S, Stahl F, Mutz KO, Scheper T, Hahn A, Schuchardt JP. Different gene expression profiles in normo- and dyslipidemic men after fish oil supplementation: results from a randomized controlled trial. Lipids Health Dis. 2012;11:105

32. Serhan CN. Pro-resolving lipid mediators are leads for resolution physiology. Nature. 2014;510:92-101.

33. Serhan CN, Clish CB, Brannon J, Colgan SP, Gronert K, Chiang N. Antimicroinflammatory lipid signals generated from dietary $\mathrm{N}-3$ fatty acids via cyclooxygenase-2 and transcellular processing: a novel mechanism for NSAID and N-3 PUFA therapeutic actions. J Physiol Pharmacol. 2000;51:643-54.

34. Serhan CN, Hong S, Gronert K, Colgan SP, Devchand PR, Mirick G, Moussignac RL. Resolvins: a family of bioactive products of omega-3 fatty acid transformation circuits initiated by aspirin treatment that counter proinflammation signals.

J Exp Med. 2002;196:1025-37.

35. Sureda A, Ferrer MD, Tauler P, Romaguera D, Drobnic F, Pujol P, Tur JA, Pons A. Effects of exercise intensity on lymphocyte $\mathrm{H}_{2} \mathrm{O} 2$ production and antioxidant defences in soccer players. Br J Sports Med. 2009;43:186-90.

36. Toft AD, Thorn M, Ostrowski K, Asp S, Moller K, Iversen S, Hermann C, Sondergaard SR, Pedersen BK. N-3 polyunsaturated fatty acids do not affect cytokine response to strenuous exercise. J Appl Physiol (1985). 2000;89: 2401-6.

37. Trappe TA, Fluckey JD, White F, Lambert CP, Evans WJ. Skeletal muscle PGF(2)(alpha) and PGE(2) in response to eccentric resistance exercise: influence of ibuprofen acetaminophen. J Clin Endocrinol Metab. 2001;86:5067-70.

38. Trappe TA, Liu SZ. Effects of prostaglandins and COX-inhibiting drugs on skeletal muscle adaptations to exercise. J Appl Physiol (1985). 2013;115:909-19.

39. Uchida MC, Nosaka K, Ugrinowitsch C, Yamashita A, Martins Jr E, Moriscot AS, Aoki MS. Effect of bench press exercise intensity on muscle soreness and inflammatory mediators. J Sports Sci. 2009;27:499-507.

40. Volek JS, Rawson ES. Scientific basis and practical aspects of creatine supplementation for athletes. Nutrition (Burbank, Los Angeles County, Calif). 2004;20:609-14.

41. Weiss T, Eckstein H, Weiss C, Diehm C. Neutrophil function in peripheral arterial occlusive disease: the effects of prostaglandin E1. Vascular medicine (London, England). 1998;3:171-5.

\section{Submit your next manuscript to BioMed Central and we will help you at every step:}

- We accept pre-submission inquiries

- Our selector tool helps you to find the most relevant journal

- We provide round the clock customer support

- Convenient online submission

- Thorough peer review

- Inclusion in PubMed and all major indexing services

- Maximum visibility for your research

Submit your manuscript at www.biomedcentral.com/submit

) Biomed Central 